\title{
CHILE ANTES DE CHILE: LOS NUEVOS TIEMPOS DEL MUSEO CHILENO DE ARTE PRECOLOMBINO
}

\author{
CHILE BEFORE CHILE: THE NEW TIMES OF THE CHILEAN MUSEUM OF \\ PRE-COLUMBIAN ART
}

\author{
Carlos Aldunate del Solar ${ }^{1}$
}

\begin{abstract}
En 2014, con motivo del 35 aniversario de su inauguración, el Museo Chileno de Arte Precolombino hizo una reflexión que culminó con una planificación estratégica. En ella se establecieron nuevos parámetros y líneas de acción, enfocados en una mayor apertura hacia nuevos públicos, incluyendo especialmente a los pueblos originarios.
\end{abstract}

Palabras claves: museos, arqueología, etnología, arte precolombino, públicos, pueblos originarios.

In 2014, on the occasion of the 35th anniversary of its inauguration, the Museo Chileno de Arte Precolombino (Chilean Museum of Pre-Columbian Art) went through a reflection process that resulted in a strategic plan. In it, new parameters and lines of action are established which focus on more openness to new audiences, with special emphasis on indigenous peoples.

Key words: Museums, archaeology, ethnology, Pre-Columbian art, audiences, indigenous peoples.

Los museos etnológicos, surgidos de los gabinetes de curiosidades europeos, se crean a partir del siglo XIX como una forma de mostrar las culturas exóticas. Antes de crearse los museos de antropología y de acuerdo a los principios evolucionistas imperantes en aquellos tiempos, estos temas estaban tratados dentro de los Museos de Historia Natural y aún lo están en muchos países.

En los años 90 del siglo pasado surge el concepto de globalización. Se auguraba que la humanidad estaba llegando a un punto en que se acabarían las luchas entre ideologías opuestas, rindiéndose ante una economía de mercado (Fukuyama 1992). Se pronosticaba el fin de los conflictos generados por diferencias culturales, las que serían reemplazadas por una estandarización o uniformidad. Sin embargo, aunque al inicio los acontecimientos reafirmaron el concepto, la reacción de los pueblos no fue rendirse ante esta globalización sino que, por el contrario, resurgieron y se reformularon diferencias étnicas y culturales y aparecieron nuevas identidades que agrupaban a comunidades cuyos intereses debieron ser considerados por las instituciones políticas, sociales y culturales. Fue un cambio de las mentalidades que activó el inicio de los derechos de las minorías, que hoy no pueden ser ignorados por las instituciones.

Tuvieron lugar debates sobre fronteras culturales, conflictos interétnicos, etnogénesis, reivindicaciones territoriales y legales que debilitaron a los estados nación. Las comunidades reclamaron sus derechos como grupos minoritarios y los negociaron frente a los estados y la sociedad global.

No fue una coincidencia que es en esta misma época se formulara el Convenio 169 de la Organización Internacional del Trabajo (OIT), que proclama que los estados firmantes deben proteger los derechos de los pueblos originarios que viven en sus territorios y en cuya elaboración participaron representantes de las sociedades indígenas de todos los continentes.

En esa misma década, tras los acontecimientos que hemos relatado, los museos europeos hijos del colonialismo pasan a ser políticamente incorrectos y surgieron procesos de renovación de estas instituciones. El Museo de América de Madrid, por ejemplo, se renueva

\footnotetext{
${ }^{1}$ Museo Chileno de Arte Precolombino, Santiago, Chile. caldunate@ museoprecolombino.cl 
en 1992 bajo el lema de "encuentros de culturas". Los de Canadá y Norteamérica se manejaron con el concepto más avanzado de reconciliación con las sociedades indígenas y surgió el sistema de corresponsabilidad entre indígenas y Estado sobre las colecciones etnológicas. En Francia, bajo el gobierno de Chirac, se crea el Quai Branly con una variante estética, al igual que en el Louvre se crea la sala de "Las Primeras Artes". Otros usaron a los objetos para hacer una crítica al sistema colonial o para reflexionar sobre el multiculturalismo, transformándose en vehículos de pluralidad, respeto y participación. Muchos de ellos también incluyeron a los inmigrantes dentro de las comunidades minoritarias.

La gran diferencia de los museos del hemisferio norte respecto a los del sur ante esta nueva mentalidad, consiste en que para los últimos lo políticamente incorrecto y poco ético es mostrar a "los otros", puesto que ellos están aquí, al lado nuestro y la mayoría de las veces somos nosotros mismos (cf. Roige et al. 2007). En efecto en nuestro continente, en especial en los países andinos con una fuerte identidad mestiza, esto es muy evidente y muchos de sus museos están intentando ser vehículos de diálogos interculturales.

Estos acontecimientos, que afectaron principalmente a los países del hemisferio norte, tuvieron su correlato en América Latina. Los casos de Chile y Argentina son diferentes a otros países andinos con gran población indígena puesto que, desde sus inicios republicanos, construyeron sus nacionalidades ignorando e invisibilizando a las minorías étnicas. Ellas han quedado prácticamente fuera de la historia oficial y su destino, en el mejor de los casos, ha sido ser folklorizadas o patrimonializadas (Figuerero y Mengoni 2016). En Chile, el fenómeno de la globalización y el resurgimiento de las demandas étnicas tuvo particular repercusión puesto que, precisamente, la década del 90 coincidió con el fin de la dictadura militar y la vuelta a la democracia, momento en que se emiten importantes normas sobre los derechos de los pueblos originarios y se crea la Corporación Nacional Indígena (CONADI), con representantes de nueve etnias reconocidas legalmente ${ }^{1}$. Si bien esto significó un avance importante respecto de la situación anterior, 25 años más tarde estas normas legales han resultado del todo insuficientes. De hecho, el Convenio 169 de la OIT fue suscrito por Chile recién el año 2008, es decir, 20 años después de su creación. Hoy, la resolución de los conflictos indígenas se ha vuelto un problema nacional que exige medidas urgentes antes que desemboque en hechos de violencia aún mayores a los que ya están ocurriendo.

\section{El Museo Chileno de Arte Precolombino}

Este Museo es una institución creada en 1979 por la Fundación Larraín Echenique y la Ilustre Municipalidad de Santiago, sobre la base de una colección particular de arte precolombino de toda Latinoamérica donada por el destacado arquitecto don Sergio Larraín. Alojado en el antiguo Palacio de la Real Aduana, en Santiago de Chile, el museo se financia con aportes públicos y privados (Figuras 1 y 2).

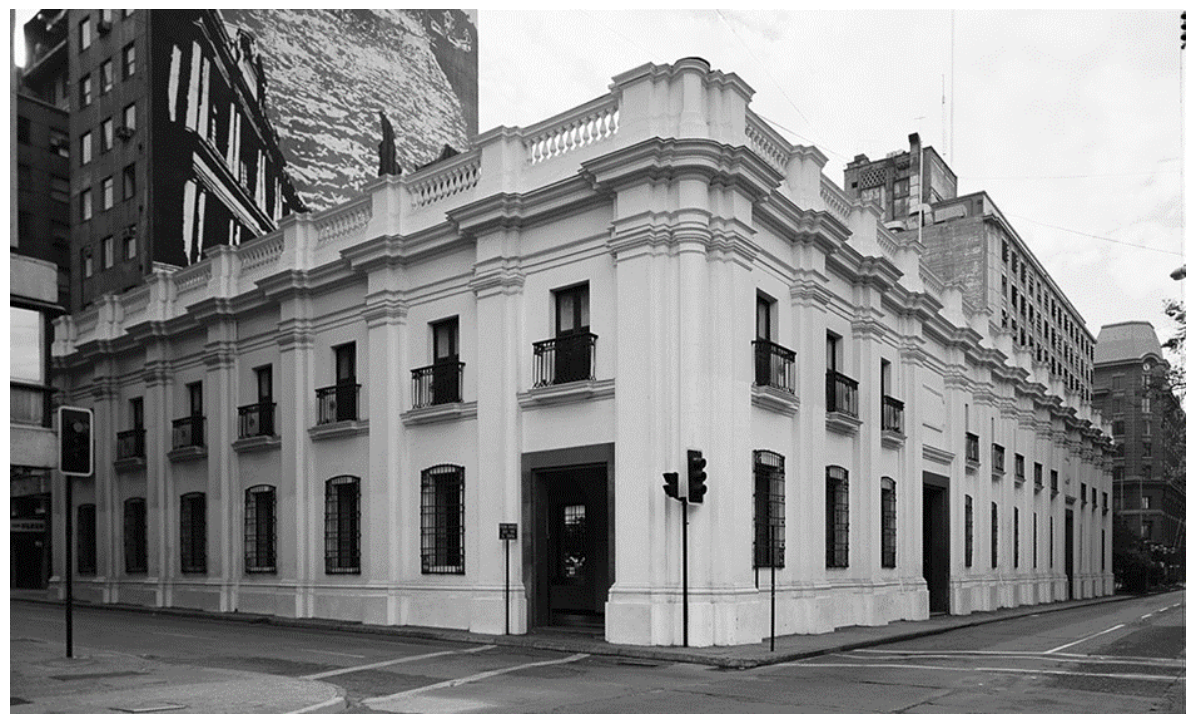

Figura 1. El Museo Chileno de Arte Precolombino está alojado en el antiguo Palacio de la Real Aduana, Monumento Nacional. The Chilean Museum of Pre-Columbian Art is housed in the old Palacio de la Real Aduana, National Monument. 


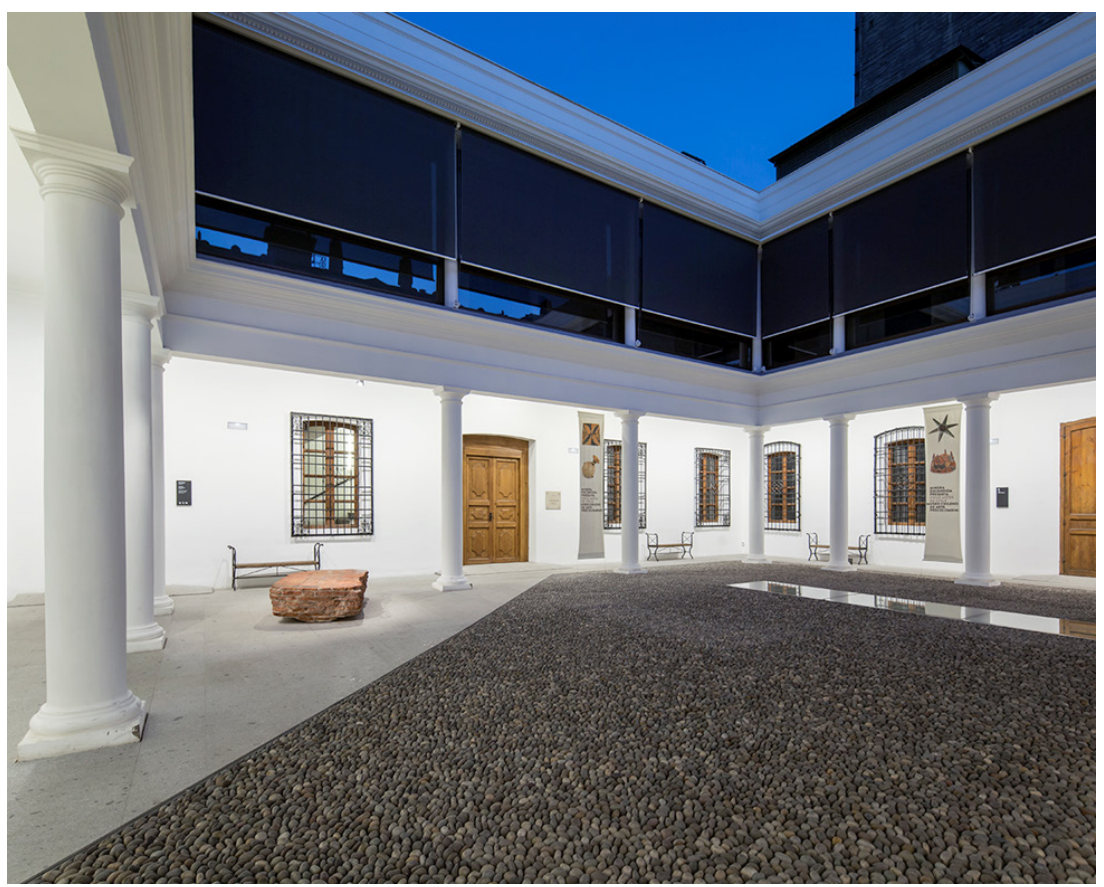

Figura 2. Patio sur del Museo.

South courtyard of the Museum.

La donación original comprende objetos que representan a las principales culturas precolombinas de América, adquiridos por el arquitecto Sr. Larraín a lo largo de su vida con un criterio esencialmente estético. La misión que legó el fundador fue un mensaje panamericanista. Remarcaba que las culturas precolombinas son anteriores a las actuales fronteras políticas que dividen a nuestros países, muchas veces sobrepasándolas y sin mostrar su relación con ellas, de modo que el museo debía servir de vehículo para la unidad de los pueblos americanos reconociéndose como herederos de un pasado común.

De esta manera, la exhibición permanente del museo está organizada en torno a las diversas áreas culturales de América -Mesoamérica, Área Intermedia, Área Andina Central, Área Sur Andina, Antillas y Amazonía- donde los objetos se identifican de acuerdo a las culturas arqueológicas a las que pertenecen, pero sin nombrar a los países de donde provienen. Los mapas de la sección Arte Precolombino, por ejemplo, no muestran los límites políticos de las naciones americanas. Las exhibiciones temporales dan cabida a temáticas diversas con colecciones propias o provenientes de otros museos de Chile o del extranjero (Figura 3).

Otro aspecto importante fue el énfasis que el fundador dio al arte por sobre disciplinas como la arqueología o antropología. De acuerdo a su mensaje, el arte toca directamente a la sensibilidad y, por lo tanto, es el mejor vehículo para estimular la curiosidad y el conocimiento de las culturas americanas pretéritas. Esto ha representado un desafío para los profesionales del museo, casi todos cientistas sociales, por la dificultad que presenta el descontextualizar a los objetos de sus contenidos históricos, funcionales y simbólicos, dando énfasis solo a la belleza. Mostrar un quipu, una tableta para aspirar alucinógenos o una vasija con glifos solo como objetos de arte, es una grave simplificación que no cumple con la misión de revelar estos objetos como continentes de la cultura de las sociedades precolombinas. Desde su fundación, el museo ha dado un trato preferente a la investigación y su planta original ha estado principalmente compuesta por arqueólogos, de manera que ha tenido que navegar entre ser un museo de arte, de arqueología o abarcar ambas disciplinas.

En estos primeros años el museo, aunque tenía colecciones etnográficas de pueblos originarios del actual territorio de Chile, solo las exhibía en exposiciones temporales o las llevaba a itinerar en el extranjero. El fundador era de la opinión de que la institución se tenía que constreñir estrictamente a su objetivo: el arte precolombino.

A inicios de este siglo, se tomó la decisión de que las exposiciones y publicaciones etnográficas 


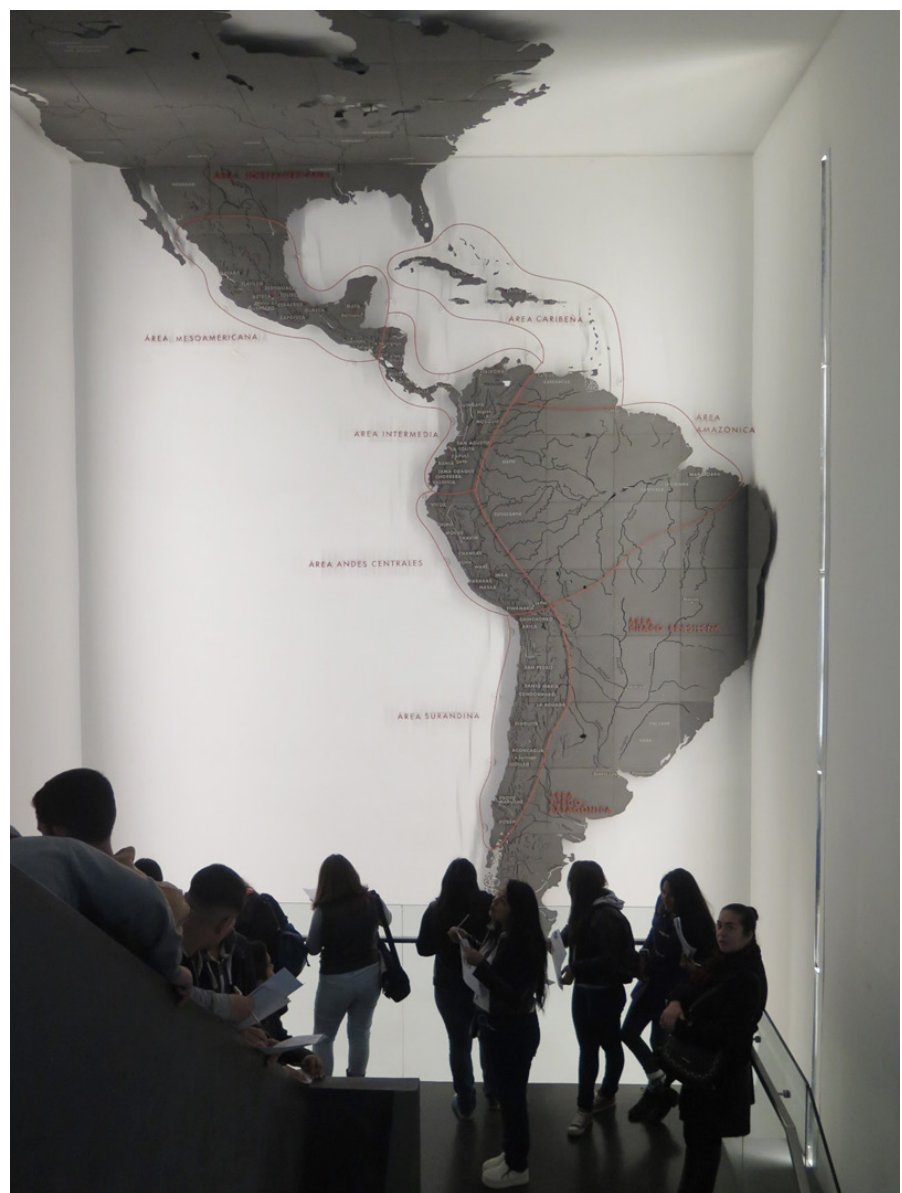

Figura 3. Mapa de América instalado en la escalera que lleva hacia las exhibiciones de arte precolombino americano.

Map of America placed on the stairway leading to the pre-Columbian American art exhibitions.

debían contar con la participación de las comunidades involucradas. Esta política se inauguró con el libro "Voces Mapuches", cuyo contenido es un relato de este pueblo hecho únicamente por historiadores, poetas, chamanes, artistas y tejedoras de esa etnia. Desde entonces, las exhibiciones itinerantes de etnografía en Chile y el extranjero se han hecho con la participación de artistas mapuches que abordan los temas tratados con textos poéticos. Estos fueron los primeros atisbos, todavía un poco temerosos, de incluir la realidad de indígenas actuales en nuestras exhibiciones, pero siempre en torno a su presente sin relación con el pasado precolombino.

\section{Chile Antes de Chile}

El museo inició su vida con exhibiciones temporales presentando, en la década de 1980, a las diversas culturas precolombinas que existieron a lo largo del actual territorio de Chile, entrelazadas con muestras sobre culturas americanas. Destacan las muestras: "Arica 10.000 años", "Tesoros de San Pedro de Atacama", "Diaguita, Pueblos del Norte Verde", "¡Mapuche!” y "Hombres del Sur”.

Particular importancia tuvo la exposición "Chile antes de Chile", realizada hace veinte años cuando el museo, considerando el desconocimiento existente en el país sobre su pasado precolombino y su consecuente menosprecio, decidió presentar una exhibición temporal sobre las sociedades prehispánicas que existieron dentro del actual territorio chileno. El título enfatizaba que antes de la conquista hispana existieron dentro de este territorio, al igual que en el continente, diversas áreas culturales: el Norte Grande, incluido en una tradición eminentemente andina (Valles Occidentales y Centro Sur Andina, sic. Lumbreras 1981); el Norte Chico y la Zona Central, estrechamente conectados con sociedades trasandinas e incanizados en el Período Tardío; el territorio Centro 
Sur también con vínculos trasandinos y una fuerte impronta mapuche y el extremo Sur, donde las antiguas tradiciones de cazadores y recolectores llegaron hasta inicios del siglo XX. Por el enorme interés que despertó, esta exhibición nos estimuló para abrir el museo a la reflexión sobre el origen diverso de las sociedades del país y sus descendientes contemporáneos, remarcando que el mundo precolombino no había muerto sino que permanecía vivo en nuestro mestizaje, lenguaje, ideologías y, muy particularmente, en los actuales pueblos originarios.

Fue así como paulatinamente creció el interés para incluir a estos primeros pueblos en nuestras actividades. En 2009 se comenzó a trabajar un proyecto que denominamos "Chile antes de Chile" para recordar aquella exhibición hecha 15 años atrás. Esta iniciativa, de gran envergadura, pretendía ampliar las instalaciones del museo para acoger una importante exhibición permanente acerca de la diversidad cultural del actual territorio chileno, esta vez incluyendo a los pueblos originarios. Se trataba de un proyecto muy ambicioso desde el punto de vista arquitectónico y estructural, puesto que la única manera de llevarlo a cabo era hacer una gran sala subterránea, excavada bajo la edificación colonial, lo que implicó superar las suspicacias de autoridades sobre los riesgos que el edificio podía correr, además de las demoras que encarecieron su realización. Desde el punto de vista curatorial, los investigadores tardaron más de dos años en preparar el proyecto, el cual fue presentado en otros espacios dentro y fuera de Santiago para probar su eficacia. La suerte determinó que en esta misma época se recibiera de una fundación privada la donación de una importante colección de casi 4.000 piezas arqueológicas y etnográficas provenientes de todo el país. Después de muchos avatares, se consiguió que este proyecto fuera aprobado por una empresa minera que auspició la realización del proyecto y se consiguió un aporte permanente del gobierno para asegurar la continuidad y sostenibilidad de esta nueva área. La realización de este proyecto demoró tres años en su ejecución, plazo durante el cual el museo permaneció cerrado porque la envergadura de las obras comprometía gran parte de sus instalaciones.

El guion abarcaba desde las primeras ocupaciones humanas hasta los actuales pueblos originarios, dividiendo el territorio en diferentes áreas culturales para mostrar la diversidad ocurrida desde la prehistoria hasta hoy. Para ello, se trabajó con cultores indígenas y representantes de las comunidades para incluir sus relatos en la exhibición y se contrató a un museógrafo extranjero de gran experiencia para que se encargara del diseño. El resultado fue una muestra que, aunque conserva las ideas de diversidad e integra a los actuales descendientes originarios, continuó privilegiando lo estético sobre los contenidos culturales pues, entre otras cosas, se excluyeron los relatos etnográficos, lo que produjo frustraciones dentro del equipo del museo.

La exhibición, sin embargo, es muy cuidada en los demás aspectos de su museografía y la sala es de grandes dimensiones, con vitrinas de avanzada tecnología y una iluminación que destaca a las piezas, que parecen flotar en el aire (Figuras 4 y 5). Pensamos que da un

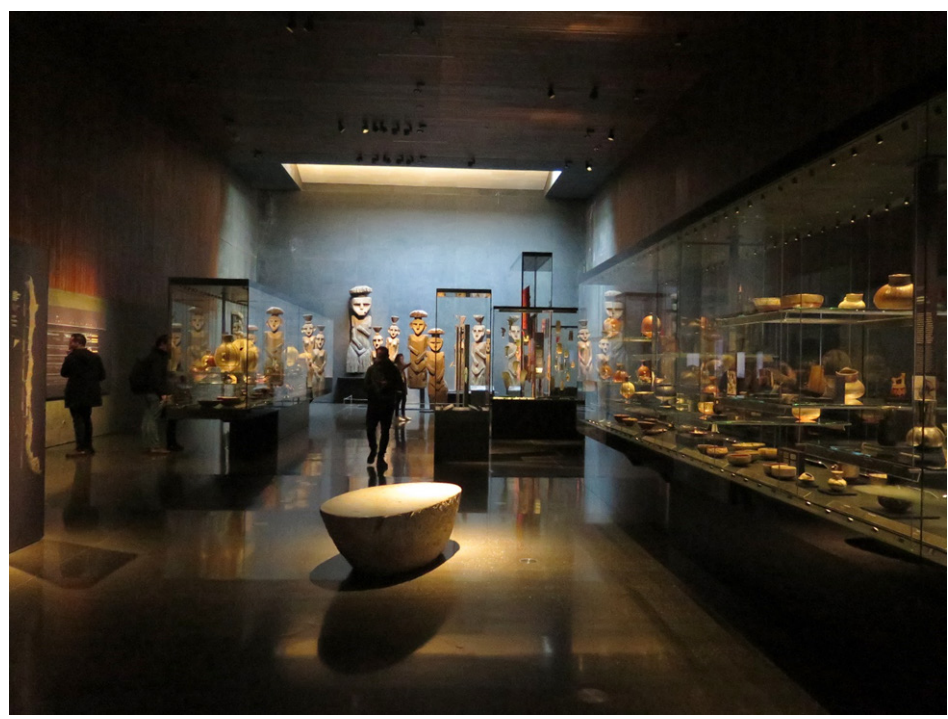

Figura 4. Sala Chile antes de Chile. Sector sur. Chile before Chile exhibition hall. Southern area. 


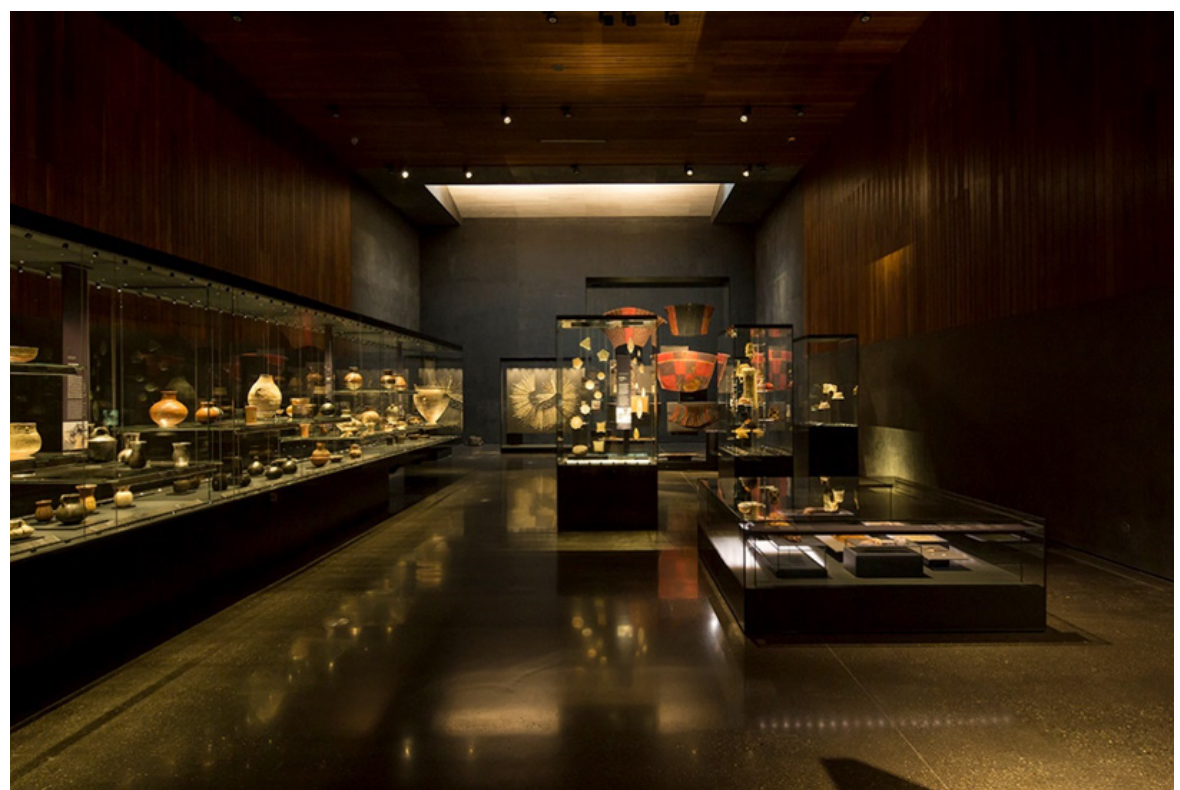

Figura 5. Sala Chile antes de Chile. Sector norte.

Chile before Chile exhibition room. Northern area.

magnífico marco al arte precolombino de las culturas que presenta y, en este sentido, cumple con el objetivo de que los chilenos se sientan orgullosos con su pasado prehispánico. Así ha sido recibida por el público.

\section{Los Nuevos Tiempos}

En una planificación estratégica llevada a cabo en 2015, se estableció que la misión del museo era conectar a las personas con las raíces indígenas de Chile y América, preservando, investigando y difundiendo su patrimonio. Dentro de las amenazas y debilidades se constató que, en los últimos años, el museo había sufrido un cierto proceso de enclaustramiento o aislamiento y necesitaba urgentemente abrirse a las diversas comunidades y públicos. Un segmento especialmente relevante y privilegiado debía ser el de los pueblos originarios; otro sector era el de los artistas contemporáneos y las comunidades de migrantes americanos, además de los estudiantes, que siempre han recibido atención preferente. Para este cometido fue necesario elaborar un agresivo plan de comunicaciones a través de los medios y redes sociales, detectar a los grupos que se interesaban por nuestra oferta cultural y elaborar políticas para acercarse a ellos y fidelizarlos. Los éxitos de esta cruzada ya se han hecho notar en la mayor audiencia que asiste a las actividades. Asimismo, ha crecido la oferta educativa y de difusión. Emprender estas acciones ha sido importante puesto que el museo recibe financiamiento de instituciones públicas a las que hay que rendir resultados.

\section{Participación con Comunidades Indígenas}

Con respecto a la participación de los pueblos originarios se han emprendido iniciativas con muy buenos resultados, siempre reconociendo que, en caso de ser atingentes, la consulta y participación de estos pueblos en las exhibiciones temporales y publicaciones es fundamental. Entre estas iniciativas destacan:

- La exhibición "Wenu Pelón” (Figura 6), a cargo de un curador y museógrafo mapuche que hizo una bella instalación inspirada en la relevancia que tienen los sueños en la cosmología de ese pueblo.

- "El Metal Sigue Hablando" (Figura 7), hecha a solicitud de plateros mapuches paramostrar sus obras. Convenimos que ellos hicieran la curaduría y la museografía bajo la supervisión del museo y en su inauguración participaron comunidades indígenas de Santiago.

- En Iquique, norte de Chile, el museo realizó una exposición sobre textilería aymara de Isluga, una comunidad del altiplano de Tarapacá, que fue curada por tejedoras de esa etnia; ellas mismas intervinieron en la conservación y restauración de los tejidos hechos por sus madres y abuelas hace medio siglo.

- La exposición "Rostros del Norte Grande" presentada en Antofagasta y San Pedro de Atacama, que contó con 


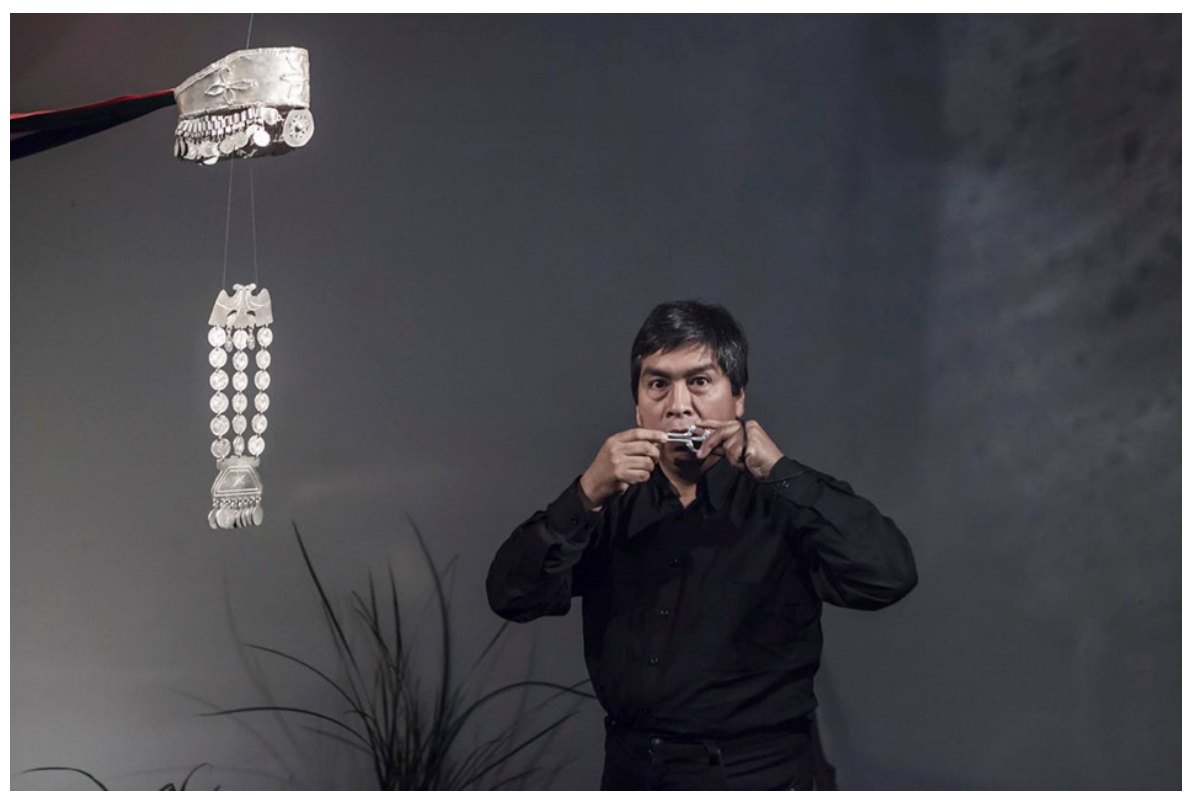

Figura 6. Exposición "Wenu Pelon".

"Wenu Pelon" exhibition.

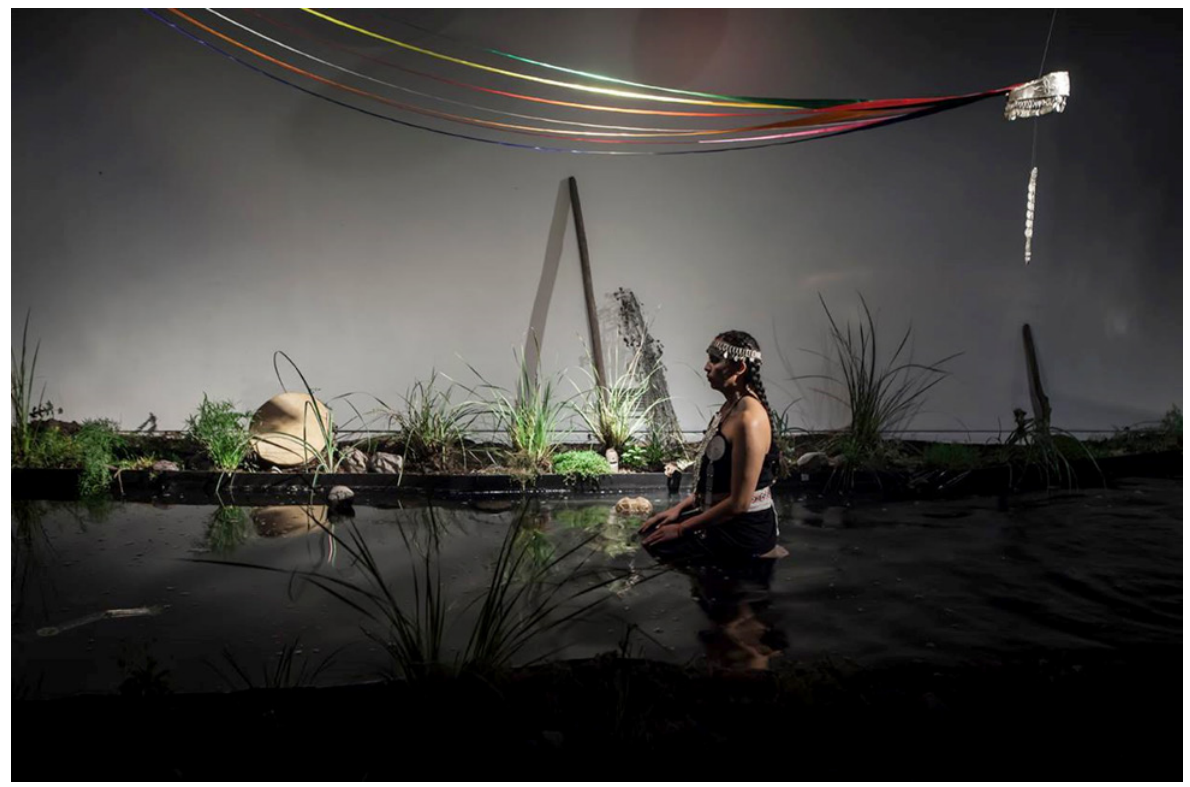

Figura 7. Exposición El Metal Sigue Hablando.

"El Metal Sigue Hablando" exhibition. 
la participación activa de la comunidad Likan Antai que expuso sus relatos junto a aquellos de los arqueólogos. - La exhibición "El Arte de ser Diaguita", que también se hizo con la participación de los actuales miembros de ese pueblo que, de esa manera, afianzaron su etnogénesis reconocida recién hace un par de años por el Estado.

- En estos momentos está en preparación una exhibición sobre arte rupestre en conjunto con la comunidad de Taira, donde se encuentran estos testimonios. Sus relatos acerca de ellos y el lugar que ocupan en su cosmología serán parte de la exhibición. Además, la comunidad recibirá un entrenamiento para resguardar los sitios y recibir turistas. Terminada la exhibición, el museo entregará todos los materiales museográficos a fin de que se haga, con recursos estatales y/o privados, un centro de interpretación en el sitio que atraiga a los turistas. Este proyecto les interesa mucho pues dará notoriedad a la comunidad y a los extraordinarios sitios rupestres de sus territorios, a la vez servirá para satisfacer las demandas que han hecho al gobierno y otras autoridades acerca de sus problemas. - Para el año 2019 el museo está preparando, junto con asociaciones de profesionales mapuches y aymaras, la exhibición "Trawun" de arte contemporáneo indígena, su objetivoes mostrarqueestas comunidades noestánencerradas en su pasado, sino que participan junto con la sociedad global en la producción de expresiones artísticas contemporáneas.

\section{Multivocalidad}

La multivocalidad ha sido una herramienta que ha ayudado mucho en este encuentro con las comunidades indígenas. Cada día es más evidente que el museo no puede actuar como dueño de una verdad absoluta ni mucho menos imponerla a quienes están ancestralmente ligados a los fenómenos que la institución investiga y difunde. El relato de los pueblos originarios que viven en el lugar donde se practican las investigaciones arqueológicas ha sido una experiencia muy enriquecedora para los curadores del museo. En nuestras publicaciones siempre se ha puesto de relieve el conocimiento ancestral de las comunidades sobre el paisaje y su particular significación, complemento necesario para la interpretación arqueológica. De igual manera, la convivencia con los pueblos originarios durante los trabajos de campo ha permitido a los investigadores un acercamiento a su ethos cultural. Esto ha significado enriquecer las interpretaciones al mismo tiempo que contrastar dos formas y dos lenguajes de igual dignidad para conocer la realidad, favoreciendo más el diálogo y sin excluir ninguna de estas maneras de comprensión e interpretación. El camino elegido ha sido presentar ambos relatos que se complementan, ofreciendo al lector o visitante dos maneras de conocer la realidad. Esto fue lo que se pretendió hacer en "Chile antes de Chile", lo que desgraciadamente no se logró debido a que, como se mencionó más arriba, el relato de los propios pueblos originarios no se incluyó en la exhibición. En ocasiones posteriores se realizó con mucho éxito, como en la exposición "Rostros del Norte Grande" en San Pedro de Atacama, donde la comunidad likan antai o atacameña participó entregando sus relatos que fueron exhibidos junto a los de los curadores. Esta fue una exhibición temporal de alta tecnología, en la que el lenguaje digital facilitó enormemente la imbricación de ambos lenguajes: uno (el de los curadores) escrito y el otro (el de miembros de la comunidad) por medios audiovisuales.

\section{Devolución de Memoria}

El museo ha participado en consultas con comunidades quechuas y aymaras de Tarapacá, que se han materializado en una petición de bibliografía e información acerca de técnicas textiles precolombinas, diccionarios aymaras y quechuas, así como publicaciones acerca de etnobotánica por el interés que manifestaron para recuperar conocimientos ancestrales de medicina. Se reprodujeron publicaciones de la biblioteca del museo, las que fueron empastadas y entregadas a estas comunidades en una ceremonia celebrada en la fiesta patronal de Iquiuca.

De nuestros archivos hemos sacado y reproducido materiales que se han entregado a comunidades originarias y rurales interesadas por saber más acerca de su patrimonio pasado y presente. En este mismo rubro, hay un programa delárea de colecciones que abrió un canal de comunicación hacia comunidades indígenas para que conozcan las colecciones y se familiaricen con tecnologías, diseños y otros aspectos de los materiales cerámicos, metales y textiles precolombinos y etnográficos, con el fin de que los artesanos puedan recuperar técnicas y motivos ancestrales.

Un reciente proyecto de investigación de etnoarqueoastronomía, encabezado por el museo junto con el Observatorio ALMA (Atacama Large Millimiter) submillimiter Array), acerca de un tramo desconocido del Qhapaq Ñan y sus implicaciones astronómicas, incluye a la comunidad atacameña likan antai de Peine, para que jóvenes investiguen y conozcan su patrimonio arqueológico y etnológico, lo custodien y se preparen como guías turísticos. 
Recientemente, hemos dado participación a las comunidades de inmigrantes peruanos en las exhibiciones realizadas en conjunto con museos de esa procedencia.

\section{Desafíos}

Los museos son instituciones surgidas en el seno de la cultura occidental hace más de dos siglos. Según mi experiencia, no hay una cabal comprensión de los pueblos indígenas acerca de qué son y de sus funciones. Más bien, en los casos que hemos observado, los ven como lugares relacionados con la muerte, con objetos separados de sus contextos funcionales, rituales y de la naturaleza y, por tanto, carentes de vida. Por otra parte, hay suspicacias sobre la manera como llegaron los objetos a estos repositorios, relacionadas con la creencia de que los museos tienenintereses económicos y comerciales. Pero quizá el rechazo más fuerte hacia los museos está en las excavaciones de tumbas, y para qué decir con la exhibición de sus contextos y restos humanos. Este problema trae a colación el rechazo hacia las excavaciones arqueológicas y una tremenda desconfianza hacia los arqueólogos, causada por malas experiencias y por los años en que se trabajaba de espaldas a las comunidades, viviendo dentro de sus territorios y sus pueblos. En Chile este problema es grave y en muchas localidades los arqueólogos son rechazados sin poder realizar sus investigaciones.

El turismo también ha traído problemas entre las comunidades originarias y la sociedad mayor, tal como ha ocurrido en múltiples lugares turísticos del mundo. Un caso emblemático es San Pedro de Atacama, donde los indígenas prácticamente abandonaron el central ayllu Conde Duque (donde se localiza el centro turístico), vendiendo o arrendando sus casas ocupadas hoy por negocios y comerciantes, y yéndose a vivir fuera del pueblo en sus estancias agrícolas y ganaderas. Ello ha provocado un acoso del turismo en esa localidad trayendo un aumento de población extraña y toda clase de problemas de convivencia con la comunidad. Esto ha sido paradigmático para la región y ha surgido una reacción entre los demás pueblos que, en repetidas veces, han dicho que no aceptarán este tipo de invasión en que los beneficios del turismo han sido secuestrados por toda clase de agentes extraños y en nada han beneficiado a la comunidad. Lo paradójico es que las atracciones turísticas de San Pedro de Atacama sean precisamente su patrimonio cultural y natural.

\section{Mirando hacia el Futuro}

A pesar de estos problemas, el cambio de mentalidades y la mayor sensibilidad de la sociedad hacia el respeto de los derechos humanos y, por qué no decirlo, a veces el mismo rechazo de las comunidades a que los científicos entren a sus territorios, han promovido una mayor conciencia entre instituciones, profesionales, académicos y museos acerca del respeto que se debe a las comunidades originarias. Hoy, la mayoría de estas instituciones están colaborando en un marco de respeto e igualdad con las sociedades minoritarias en un diálogo intercultural. El turismo, a pesar de sus incidencias negativas, es uno de los aspectos que concitan intereses entre arqueólogos, museos y comunidades para proteger y poner en valor el patrimonio material e inmaterial. Muchos pueblos originarioshan pedidolacolaboraciónde investigadores para legitimar sus demandas territoriales, de aguas y otros recursos, trazando su descendencia desde el pasado hasta la actualidad. Además, les solicitan respaldo para documentar y reforzar el aprovechamiento de los recursos que les da su patrimonio arqueológico en planes turísticos. De esta manera, los guías de turistas de las comunidades podrán poner su voz acerca de las interpretaciones de su propia historia. El Estado, finalmente, también se verá favorecido al compartir su responsabilidad en el resguardo del patrimonio con las comunidades y los científicos.

Tal es el estado que presentan los museos en Chile, mismo que, probablemente, se encuentra más alejado del alcanzado por muchas instituciones de otros países andinos que llevan un camino más largo y fructífero gracias a la relevancia numérica, cultural y política que en ellos tienen las sociedades indígenas.

\section{Referencias Citadas}

Figuerero, M. y G. Mengoni 2016. Sumando voces- una experiencia en el trabajo conjunto entre arqueólogos y comunidades originarias de Santa Cruz, Argentina. XIX Congreso Nacional de Arqueología Argentina, pp. 2262-2265.

Fukuyama, F. 1992. El Fin de la Historia y el Último Hombre. Editorial Planeta, Barcelona.
Roige y Ventura, X.2007. Museos etnológicos: entre la crisis y la redifición. Quaderns-e de l'Institute Català d'Antropologia 9.

Lumbreras, L.G. 1981. Arqueología de la América Andina. Editorial Milla Batres, Lima. 


\section{Nota}

${ }^{1}$ La ley 19.253 (art.1) reconoce a los siguientes pueblos originarios: Aymara, Quechua, Likan Antai (Atacameños), Colla, Diaguita, Rapa Nui, Mapuche, Kawesqar y Yagan. Según la encuesta Casen realizada en 2013, la población indígena del país sumaba 1.565 .915 personas, de las cuales los Aymara son 120.621 (7,7\%), los Quechua 30.019 (1,9\%, los Likan Antai (o Atacameños) 23.237 (1,5\%), los Colla $12.579(0,8 \%)$, los Diaguita $50.653(3,2 \%)$, Los Rapa Nui $4.467(0,2 \%)$, los Mapuche $1.321 .717(84,4 \%)$, los Kawesqar $876(0,1 \%)$ y los Yagan $871(0,1 \%)$. 